\title{
PENAMBAHAN PERTURBATION TRAINING PADA CORE STABILITY EXERCISE LEBIH BAIK DARIPADA CORE STABILITY EXERCISE DALAM PENINGKATAN KESEIMBANGAN LANSIA DI MENGWI-BADUNG
}

\author{
Putu Mulya Kharismawan ${ }^{1}$, RA Tuty Kuswardhani ${ }^{2}$, Wahyuddin ${ }^{3}$, Anak Agung Sagung \\ Sawitri $^{4}$, I Nyoman Adiputra ${ }^{5}$, S. Indra Lesmana ${ }^{6}$ \\ ${ }^{1}$ Program Studi Magister Fisiologi Keolahragaan Universitas Udayana, Denpasar \\ ${ }^{2}$ Divisi Geriatri, Departemen Ilmu Penyakit Dalam, Universitas Udayana, Denpasar \\ ${ }^{3,6}$ Fakultas Fisioterapi Universitas Esa Unggul, Jakarta \\ ${ }^{4,5}$ Fakultas Kedokteran Universitas Udayana, Denpasar
}

\begin{abstract}
ABSTRAK
Pendahuluan: Jatuh adalah masalah besar yang sering terjadi pada populasi lansia. Salah satu penyebabnya adalah penurunan kesimbangan pada lansia. Tujuan Penelitian: untuk membuktikan penambahan perturbation training pada core stability exercise lebih baik dalam meningkatkan keseimbangan lansia dibandingkan dengan core stability exercise. Metode: Penelitian ini merupakan penelitian eksperimental dengan rancangan pre dan post test control group design. Jumlah sampel penelitian 22 orang dan terbagi ke dalam dua kelompok. Kelompok 1 mendapat perlakuan perturbation training dan core stability exercise, sedangkan Kelompok 2 dmendapat perlakuan core stability exercise. Pengukuran keseimbangan menggunakan Berg balance scale. Hasil: Uji Paired Sample t-test pada Kelompok 1 dan Kelompok 2 didapatkan nilai $\mathrm{p}=0,001(\mathrm{p}<0,025)$ yang menunjukkan bahwa terdapat perubahan yang signifikan setelah pemberian latihan pada masing-masing kelompok. Selanjutnya, uji perbandingan antara Kelompok 1 dengan Kelompok 2 menggunakan independent sample $t$-test dan didapatkan nilai $\mathrm{p}=0,015(\mathrm{p}<0,025)$. Hal ini menunjukkan ada perbedaan yang signifikan antara kedua kelompok. Simpulan: penambahan perturbation training pada core stability exercise lebih baik daripada core stability exercise dalam meningkatkan keseimbangan lansia.
\end{abstract}

Kata Kunci: keseimbangan lansia, perturbation training, core stability exercise, Berg balance scale

\section{ADDITIONAL PERTURBATION TRAINING ON CORE STABILITY EXERCISE BETTER THAN CORE STABILITY EXERCISE TO IMPROVE BALANCE IN ELDELRY AT MENGWI-BADUNG}

\section{ABSTRACT}

Background: falls is one of the major problems that often occur in the elderly population. It caused the decrease of balance in elderly. Purpose: to prove addition perturbation training on core stability exercise better than core stability exercise to improve balance in elderly. Method: This research is an experiment research design with pre and post test control group design. These samples included 22 people who were divided into two groups. Group 1 has given perturbation training and core stability exercise, while Group 2 has given core stability exercise. Measurement of balance measured using a Berg balance scale. Result: Paired t-test at Group 1 and Group 2 showed value $\mathrm{p}=0.001(\mathrm{p}<0.025)$, this results showed a significant balance increase in each groups. Then independent sample t-test between Group 1 and Group 2 showed value of $p=0.015(\mathrm{p}<0.025)$. It 
results showed significant difference between Group 1 and Group 2. Conclusion: additional perturbation training on core stability exercise better than core stability exercise to improve balance in elderly.

Keywords: Elderly balance, perturbation training, core stability exercise, Berg balance scale

\section{PENDAHULUAN}

Jatuh adalah masalah besar yang sering terjadi pada populasi lansia dan penyebab utama cedera pada lansia. Di Amerika Serikat, 20-30\% kejadian jatuh pada lansia menyebabkan cedera sedang hingga berat. Hal ini menyebabkan. penurunan mobilitas dan kemandirian, dan meningkatkan resiko dari kematian. ${ }^{1}$

Core stability merupakan salah satu latihan yang dapat diberikan untuk memperbaiki keseimbangan pada lansia. Menurut penelitian yang telah dilakukan oleh Core stability exercise bertujuan untuk mengaktivasi otot-otot core yang terdapat dalam tubuh sehingga dapat meningkatkan stabilitas tubuh. Latihan ini dapat membentuk postur yang sesuai selama melakukan gerakan dan sebagai dasar untuk seluruh pergerakan. Postur yang baik akan membentuk stabilitas tubuh yang baik sehingga dapat meningkatkan keseimbangan tubuh secara statis maupun dinamis. ${ }^{2}$ Pada lansia selain terjadi penurunan kontrol terhadap postur, juga terjadi penurunan respon tubuh terhadap perubahan posisi yang terjadi di lingkungan. Pemberian core stability exercise hanya berfokus pada kontrol postural saja. Oleh karena itu diperlukan latihan yang bertujuan untuk meningkatkan respon tubuh lansia terhadap perubahan posisi, agar menghasilkan respon cepat sehingga keseimbangan lansia akan lebih baik.

Perturbation training merupakan salah satu latihan yang dapat diberikan untuk meningkatkan respon lansia terhadap perubahan posisi. Perturbation training merupakan latihan yang bertujuan memberikan gaya eksternal dan gangguan pada tubuh untuk meningkatkan neuromuscular awareness, neuromuscular response dan stabilitas dinamis tubuh. Latihan ini juga bertujuan untuk menimbulkan respon yang cepat, spesifik dan efisien pada tubuh saat terdapat gaya eksternal yang terjadi. ${ }^{3}$ Pemberian perturbation training pada lansia akan melatih proprioseptif, sehingga respon yang dihasilkan untuk menjaga keseimbangan tubuh lebih baik. Hasil penelitian Pathan dan Kumar menunjukkan pemberian perturbation training dapat meningkatkan keseimbangan pada pasien stroke. ${ }^{4}$

Berdasarkan pemaparan tersebut, disimpulkan bahwa pemberian core stability exercise akan membantu membentuk stabilitas postural yang baik, sedangkan perturbation training akan melatih respon proprioceptif untuk menghasilkan respon yang cepat untuk menjaga posisi tubuh saat statis dan dinamis. Kedua latihan tersebut memiliki target yang berbeda untuk membentuk keseimbangan pada lansia. Penambahan perturbation training pada core stability exercise diharapkan akan meningkatkan balance recovery reaction, sehingga diharapkan akan meningkatkan keseimbangan lansia secara signifikan.

\section{METODE PENELITIAN}

Rancangan penelitian adalah eksperimental dengan Kelompok 1 diberikan perturbation training dan core stability exercise, sedangkan Kelompok 2 hanya diberikan core stability exercise. Pengukuran keseimbangan menggunakan Berg Balance Scale (BBS).

Penelitian ini dilakukan di Banjar Lebah Sari, Desa Gulingan, Mengwi-Badung, pada Bulan Februari - Maret 2018. Penelitian dilakukan dengan frekuensi 3 kali seminggu 
yang berlangsung selama 6 minggu. Sampel berjumlah 11 orang di masing-masing kelompok, yang diseleksi dari populasi lansia di Banjar Lebah Sari.

\section{HASIL PENELITIAN}

\section{Karakteristik Subjek Penelitian}

Tabel 1.

Karakteristik Sampel

\begin{tabular}{cccc}
\hline Karakteristik & Kelompok 1 & Kelompok 2 & Nilai p \\
\hline Jenis Kelamin(\%) & & & \\
Laki-Laki & 18,2 & 18,2 & 1,00 \\
Perempuan & 81,8 & 81,8 & \\
Umur (tahun) & & & \\
Mean \pm SD & $70,45 \pm 1,81$ & $69,91 \pm 1,81$ & 0,488 \\
IMT & & & \\
Mean \pm SD & $25,01 \pm 3,82$ & $24,17 \pm 3,94$ & 0,616 \\
\hline
\end{tabular}

Berdasarkan Tabel 1 menunjukkan bahwa pada karakteristik jenis kelamin, umur, dan IMT nilai $\mathrm{p}>0,05$. Data tersebut menunjukkan bahwa untuk seluruh karakteristik sampel antara kedua kelompok memiliki karakteristik yang hamper sama.

\section{Uji Normalitas dan Homogenitas}

Tabel 2.

Uji Normalitas dan Homogenitas

\begin{tabular}{|c|c|c|c|}
\hline \multirow{3}{*}{$\begin{array}{c}\text { Kelompok } \\
\text { Data }\end{array}$} & \multicolumn{2}{|c|}{ Uji Normalitas * } & \multirow{3}{*}{$\begin{array}{c}\text { Uji } \\
\text { Homogenitas** } \\
\text { Nilai p }\end{array}$} \\
\hline & $\begin{array}{c}\text { Kelompok } \\
1 \\
\end{array}$ & $\begin{array}{c}\text { Kelompok } \\
2 \\
\end{array}$ & \\
\hline & Nilai $p$ & Nilai $p$ & \\
\hline $\begin{array}{l}\text { Sebelum } \\
\text { Pelatihan }\end{array}$ & 0,641 & 0,945 & 0,838 \\
\hline $\begin{array}{l}\text { Sesudah } \\
\text { Pelatihan }\end{array}$ & 0,128 & 0,448 & - \\
\hline
\end{tabular}

*Uji Normalitas dengan Saphiro Wilk test

**Uji Homogenitas dengan Levene's test

Berdasarkan Tabel 2, keseluruhan data memiliki nilai $\mathrm{p}>0,05$ dan menunjukkan seluruh data pada masing-masing kelompok memiliki berdistribusi normal. Sehingga uji hipotesis yang digunakan adalah parametrik. Uji homogenitas didapatkan nilai $\mathrm{p}=0,838$ ( $\mathrm{p}$ $>0,05)$ yang menunjukkan data homogen pada sebelum pelatihan

\section{Uji Beda Rerata Keseimbangan Lansia}

Tabel 3.

Paired Sample t-test

\begin{tabular}{llll}
\hline & $\begin{array}{c}\text { Rerata } \\
\text { Sebelum } \\
\text { Latihan }\end{array}$ & $\begin{array}{c}\text { Rerata } \\
\text { Setelah } \\
\text { Latihan }\end{array}$ & Nilai p \\
\hline Kelompok 1 & $36,18 \pm 1,61$ & $40,64 \pm 1,43$ & 0,001 \\
Kelompok 2 & $35,91 \pm 1,76$ & $39,09 \pm 1,51$ & 0,001 \\
\hline
\end{tabular}

Bedasarkan data pada Tabel 3 diperoleh nilai $\mathrm{p}=0,001(\mathrm{p}<0,025)$ pada Kelompok 1 yang menunjukkan adanya peningkatan keseimbangan lansia setelah pemberian latihan pada perturbation training dan core stability exercise. Pada Kelompok 2 nilai $\mathrm{p}=0,001(\mathrm{p}<0,025)$ yang menunjukkan adanya peningkatan pada keseimbangan lansia pemberian setelah core stability exercise.

\section{Uji Komparasi Keseimbangan Lansia Sebelum dan Sesudah Latihan antar Kelompok}

Tabel 4.

Independent Sample t-test

Kelompok N Rerata \pm SB Nilai $\mathrm{p}$

\begin{tabular}{|c|c|c|c|c|}
\hline \multirow{2}{*}{$\begin{array}{l}\text { Sebelum } \\
\text { Latihan }\end{array}$} & Kelompok 1 & 11 & $36,18 \pm 1,61$ & \multirow{2}{*}{0,708} \\
\hline & Kelompok 2 & 11 & $35,91 \pm 1,76$ & \\
\hline \multirow{2}{*}{$\begin{array}{l}\text { Sesudah } \\
\text { Latihan }\end{array}$} & Kelompok 1 & 11 & $40,64 \pm 1,43$ & \multirow{2}{*}{0,015} \\
\hline & Kelompok 2 & 11 & $39,09 \pm 1,51$ & \\
\hline
\end{tabular}

Berdasarkan Tabel 4 menunjukkan bahwa pada data sesudah pelatihan nilai $\mathrm{p}=$ $0,015$ ( $\mathrm{p}<0,025)$. Hal ini menunjukkan 
adanya perbedaan yang signifikan pada Kelompok 1 (perturbation training dan core stability exercise) dan Kelompok 2 (core stability exercise). Pada Kelompok 1 terjadi peningkatan keseimbangan sebesar 4,45 (12,3 $\%$ ), sedangkan pada Kelompok 2 terjadi peningkatan keseimbangan sebesar 3,18 $(8,8 \%)$. Hal tersebut menunjukkan bahwa pada Kelompok 1 terjadi peningkatan keseimbangan yang lebih baik pada lansia daripada Kelompok 2.

\section{PEMBAHASAN}

\section{Core Stability Exercise dapat Meningkatkan Keseimbangan Tubuh Lansia di Mengwi-Badung}

Berdasarkan beberapa kajian teori, core stability exercise merupakan salah satu latihan yang diberikan untuk membentuk postural yang baik. Otot-otot yang menjadi target utama adalah deep muscle yang terletak pada abdomen, spine, pelvic, dan shoulder. ${ }^{4}$ Jadi prinsip dari core stability exercise adalah untuk melatih dan mengaktivasi otot-otot core yang merupakan otot-otot postural tubuh. Teraktivasinya otot-otot core akan meningkatkan kestabilan dan keseimbangan pada tubuh.

Menurut Frank, et al., aktivasi otototot core akan meningkatkan intra abdominal pressure (IAP) yang dapat meningkatkan stabilitas trunk dan menurunkan beban pada spine. ${ }^{5}$ Kontribusi dari diafragma pada IAP sangat penting untuk memberikan stabilitas pada trunk sehingga gerakan-gerakan pada ekstremitas menjadi lebih optimal. Sedangkan pada otot-otot abdominal, kontraksi dari otot transversus abdominalis meningkatkan IAP dan tekanan fascia thorakolumbal. Jadi kontraksi dari diafragma, pelvic floor, dan transversus abdominalis berperan dalam regulasi dari IAP dan menyediakan stabilitas postural dari anterior lumbopelvic sehingga disebut deep core dan bekerja secara automatis tanpa disadari serta menjadi awal suatu gerakan. Kontraksi otot-otot core yang meningkatkan IAP terjadi sebelum gerakan pada segmen anggota gerak. Dalam hal ini, sebelum menggerakkan anggota gerak, akan diawali dengan peningkatan stabilitas dari spine (core of the body) terlebih dahulu. Sehingga gerakan pada anggota gerak akan menjadi lebih stabil dan keseimbangan saat bergerak ataupun diam akan lebih baik.

Penelitian yang dilakukan oleh Suadnyana di Badung-Bali terkait dengan pemberian core stability exercise pada lansia selama enam minggu, menunjukkan hasil yang signifikan terhadap peningkatan keseimbangan lansia. ${ }^{7}$

\section{Penambahan Perturbation Training pada Core Stability Exercise dapat Meningkatkan Keseimbangan Tubuh Lansia di Mengwi-Badung}

Berdasarkan beberapa kajian teori, perturbation training merupakan suatu latihan yang diberikan dengan memberikan gaya eksternal yang dapat mengacaukan kestabilan dan keseimbangan tubuh yang bertujuan untuk meningkatkan neuromuscular awareness, neuromuscular response, dan stabilitas tubuh. ${ }^{7}$ Perturbation training merupakan latihan spesifik yang bertujuan untuk melatih balance-recovery reaction. Balance recovery reaction sangat penting dalam keseimbangan tubuh, karena berkaitan dengan kemampuan seseorang untuk merespon secara efektif adanya gaya eksternal yang berpotensi mengganggu keseimbangan. ${ }^{9}$ Perturbation training melatih respon spesifik seseorang terhadap gangguan sehingga dapat mempertahankan posisi tubuh dalam keadaan stabil dan seimbang. Respon yang dihasilkan dalam perturbation training, harus spesifik, cepat, dan efisien. ${ }^{3}$

Menurut Raine, et al. di dalam buku Bobath Concept menyebutkan bahwa selama perturbation akan terjadi respon postural sebagai langkah antisipasi untuk menjaga keseimbangan tubuh. Respon yang terjadi melibatkan motor planning pada higher level yang meliputi serebelum, basal ganglia, 
korteks serebri dan bentuk mekanisme feedforward untuk adaptasi sistem sensoris dan motoris pada dasar dari pengalaman gerak sebelumnnya. Walaupun aktivitas kontrol postural dan keseimbangan dipengaruhi oleh korteks, sistem regulasinya terdapat pada brainstem. respon automatis yang terjadi saat pemberian perturbation training, informasinya secara terus menerus diterima oleh sistem sensoris yaitu: visual, vestibular, dan somatosensoris. Rekruitmen otot-otot yang tepat untuk menghasilkan strategi kontrol postur yang cepat melibatkan medial descending system, yang meliputi sistem vestibulospinal dan pontine retikulospinal. Sistem ini berperan pada otot-otot axial dan proksimal yang terlibat dalam memperbaiki postur tegak dan integrasi gerakan antara ekstremitas dan trunk. Lateral descending system yang meliputi sistem kortikospinal dan rubrospinal, bertanggung jawab untuk rekruitmen otot-otot distal dan membantu kontrol postural dengan menghasilkan gerakan yang selektif. ${ }^{9}$

Penelitian oleh Kurz di Brazil, yang melakukan penelitian tentang perturbation training terhadap peningkatan kontrol keseimbangan dan gerakan melangkah volunteer pada lansia. Hasil penelitian tersebut menunjukkan bahwa pemberian perturbation training pada lansia dapat meningkatkan kontrol dari keseimbangan dan gerakan volunteer melangkah yang merupakan faktor resiko dari jatuh pada lansia. Hal ini dikarenakan pemberian perturbation training akan menstimulasi sistem saraf pusat untuk membentuk peningkatan adaptasi terhadap kontrol proaktif dan reaktif terhadap stabilitas dan keseimbangan. ${ }^{1}$

Penelitian lainnya yang dilakukan oleh Pathan dan Kumar di India, yang melakukan penelitian tentang perturbation training terhadap peningkatan keseimbangan, fungsional, dan mobilitas pada pasien stroke. Hasil penelitian tersebut menunjukkan bahwa pemberian manual perturbation training yang dikombinasikan dengan beberapa latihan konvensional fisioterapi dapat meningkatkan keseimbangan, fungsional, dan mobilitas pada pasien dengan riwayat stroke. ${ }^{4}$ Pemberian perturbation training akan melatih reactive balance control yang berperan penting mempertahankan keseimbangan. Selain itu pemberian perturbation training dengan arah yang bervariasi akan meningkatkan input vestibular yang berpengaruh terhadap kontrol postural.

Penambahan perturbation training pada core stability exercise akan saling bersinergi untuk membentuk kestabilan dan keseimbangan pada tubuh. Core stability exercise akan membentuk kontrol postural yang baik, dan perturbation training akan melatih respon tubuh yang cepat sehingga terbentuk keseimbangan tubuh yang baik.

\section{Perturbation Training dan Core Stability Exercise Lebih Meningkatkan Kesimbangan Lansia daripada Core Stability Exercise di Mengwi-Badung}

Berdasarkan hasil penelitian ini, maka hipotesis ketiga yang menyatakan bahwa penambahan perturbation training pada core stability exercise lebih baik daripada core stability exercise saja dalam peningkatannya yang lebih besar pada keseimbangan lansia terbukti. Penambahan perturbation training pada core stability exercise dapat melatih balance recovery reaction pada lansia.

Menurut Guccione, et al., dalam buku Geriatric Physical Therapy, pada lansia terjadi proses degeneratif yang salah satunya menyebabkan penurunan kestabilan dan keseimbangan tubuh lansia. Proses degeneratif ini menyababkan penurunan kontrol postural pada lansia dan respon integrasi sistem kesimbangan. ${ }^{10}$ Menurut Kisner dan Colby, pemberian core stability exercise akan melatih mekanisme IAP yang akan berpengaruh pada integrated spinal stabilizing system. Mekanisme inilah yang akan membentuk kontrol postural yang berdampak pada peningkatan kestabilan dan keseimbangan pada tubuh lansia. Pemberian 
core stability exercise juga dapat meningkatkan kekuatan otot-otot trunk, abdominal, lumbal dan pelvis sehingga dapat memberikan stabilitas yang baik pada tubuh untuk menghasilkan pergerakan yang efisien. ${ }^{11}$

Menurut Mansfield, pemberian perturbation training akan melatih balance recovery reaction yang berpengaruh terhadap respon antar sistem integrasi keseimbangan. Balance recovery reaction berkaitan dengan kemampuan seseorang untuk merespon secara efektif terhadap gaya eksternal yang dapat mengganggu keseimbangan. ${ }^{8}$ Pada lansia respon ini juga menurun, sehingga menjadi salah satu penyebab resiko jatuh pada lansia.

Kelebihan penambahan perturbation training pada core stability exercise adalah dapat meningkatkan respon tubuh lansia terhadap perubahan gaya yang terjadi. Pemberian core stability exercise saja hanya berfokus pada peningkatan kontrol postural tubuh dengan aktivasi otot-otot core tubuh. Pada proses degeneratif bukan hanya kontrol postural saja yang mengalami penurunan, namun kemampuan tubuh untuk merespon perubahan gaya dalam mempertahankan keseimbangan juga mengalami penurunan. Oleh karena itu pemberian perturbation training sangat penting untuk meningkatkan balance recovery reaction sehingga dapat meningkatkan respon tubuh lansia terhadap perubahan gaya terjadi. Pemberian core stability exercise lebih berfokus pada peningkatan keseimbangan tubuh secara statis. Sedangkan pemberian perturbation training akan meningkatkan keseimbangan dinamis tubuh. Jadi dengan memberikan perturbation training dan core stability exercise dapat memberikan stabilitas dan keseimbangan pada lansia saat posisi statis ataupun dinamis.

Berdasarkan beberapa kajian teori dan hasil penelitian dapat disimpulkan bahwa core stability exercise dapat meningkatkan keseimbangan lansia dengan meningkatkan kontrol postural pada lansia. Sehingga lansia dapat mengontrol posturnya dalam posisi yang terbaik untuk mempertahankan kestabilan dan keseimbangan tubuhnya. Sedangkan perturbation training dapat meningkatkan keseimbangan lansia dengan melatih balance recovery reaction. Meningkatnya balance recovery reaction akan meningkatkan respon tubuh lansia terhadap gerakan yang dilakukan dan perubahan gerakan yang terjadi. Oleh karena itu mengkombinasikan perturbation training dan core stability exercise akan sangat baik untuk meningkatkan keseimbangan lansia karena targetnya berbeda dan keduanya bekerja saling bersinergi.

Berdasarkan hasil dari penelitian ini, tentunya pelatihan ini dapat dijadikan pertimbangan untuk dijadikan program rutin kepada lansia dalam meningkatkan keseimbangan dan mengurangi resiko jatuh pada lansia. Selain itu, selama melakukan penelitian tidak ada efek samping yang dirasakan oleh subjek saat dan setelah melakukan latihan. Hanya saja sebelum melakukan latihan harus dilakukan pemeriksaan vital sign (tekanan darah, pernafasan, denyut nadi), pemeriksaan fisik pada subjek penelitian, serta assessment riwayat penyakit pada subjek penelitian. Kedepannya diharapkan penelitian ini juga bisa dijadikan pedoman untuk mengembangkan keilmuan dan penelitian, sehingga keterbatasan-keterbatasan yang dialami saat penelitian ini dapat diatasi untuk hasil yang lebih baik kedepannya.

\section{KETERBATASAN PENELITIAN}

1. Penelitian ini baru menyimpulkan peningkatan keseimbangan lansia untuk jangka pendek saja. Penelitian selanjutnya diharapkan untuk menambah waktu pelatihan untuk melihat efisiensi dan efektifitas pelatihan dalam jangka panjang.

2. Pengukuran keseimbangan dalam penelitian ini masih dilakukan terbatas di awal dan di akhir penelitian. Penelitian selanjutnya diharapkan pengukuran 
dilakukan setiap minggu untuk melihat progresifitas dari pelatihan setiap minggu sehingga dapat dilakukan evaluasi setiap minggunya.

3. Pada penelitian ini, faktor aktivitas fisik yang dilakukan oleh sampel di luar jadwal penelitian tidak dapat dikontrol. Hal ini dapat mempengaruhi penelitian dan diharapkan untuk mengontrol variabel ini untuk mendapatkan hasil yang lebih akurat.

\section{SIMPULAN}

1. Pemberian core stability exercise dapat meningkatkan keseimbangan lansia di Mengwi-Badung.

2. Pemberian perturbation training pada core stability exercise dapat meningkatkan keseimbangan lansia di Mengwi-Badung.

3. Penambahan perturbation training pada core stability exercise lebih baik daripada core stability exercise dalam peningkatan keseimbangan lansia di Mengwi-Badung.

\section{DAFTAR PUSTAKA}

1. Kurz I, Gimmon Y, Shapiro A, Debi R, Snir Y dan Melzer I. 2016. Unexpected Perturbation Training Improves Balance Control and Voluntary Stepping Times in Older Adults - A Double Blind Randomized Control Trial. BMC Geriatric, 16(58): $1-11$.

2. Irfan, M. 2012. Fisioterapi Bagi Insan Stroke. Yogyakarta: Graha Ilmu

3. Kinandana P, Nurmawan PS, Adiputra N. 2016. Intervensi Ultrasound dan Perturbation Training Lebih Efektif Dibandingkan dengan Ultrasound dan Close Kinematic Chain Exercise Terhadap Peningkatan Kemampuan Fungsional pada Penderita
Osteoarthritis Genu Grade 2. Majalah Ilmiah Fisioterapi Indonesia, 1(1)

4. Pathan N dan Kumar C. 2016. Effectiveness of Perturbation Exercises in Improving Balance, Function and Mobility in Stroke Patients: A Randomized Controlled Trial. J Nov Physiother, 6(2): 1-7

5. Frank C, Kobesova A, dan Kolar P. 2013. Dynamic Neuromuscular Stabilization and Sports Rehabilitation. The International Journal of Sports Physical Therapy. 2013 8(1), pp 62

6. Suadnyana, Astiti IA. 2017. Pelatihan 12 Balance Exercise Lebih Meningkatkan Keseimbangan Dibandingkan Core Stability Exercise Pada Lansia Di Banjar Pembungan. Desa Sesetan, Kecamatan Denpasar Selatan [Tesis]. Bali : Universitas Udayana

7. Brotzman SR dan Manske RC. 2011. Clinical Orthopaedic Rehabilitation. An Evidence Based Approach. Third Edition. Philadelphia. Elsevier: 219222. Available at: https://books.google.co.id (diakses 110-2017).

8. Mansfield A, Peters AL, Liu BA, Maki BE. 2007. A Perturbation-Based Balance Training Program for Older Adults: Study Protocol for a Randomised Controlled Trial. BMC Geriatrics, 7(12): 1-14

9. Raine S, Meadows L, LynchElleringthon M. 2009. Bobath Concept: Theory and Clinical Practice in Neurological Rehabilitation. Singapore: WileyBlackwell 
10. Guccione, A., Wong, R. dan Avers, D., 2012. Geriatric Physical Therapy $3^{\text {rd }}$ edition. Missouri: Elsevier Mosby

11. Kisner C dan Colby LA. 2012. Therapeutic Exercise Foundations and Techniques. Philadelphia: F.A. Davis Company 